\title{
The Analysis of Block-type Business Office Park Landscape Design -- Taking Hefei Financial Village Phase One as Example
}

\author{
Yanan Zhang 1, a \\ ${ }^{1}$ School of Art and Media, Hubei Business College, Wuhan 430079, China. \\ a158752449@qq.com
}

\begin{abstract}
Keywords: Block-type business office park, landscape design, bottom boundary, green Landscape.
\end{abstract}

\begin{abstract}
Hefei Financial Village is the masterpiece from the leading domestic industrial real estate block operator -- Optics Valley Union in 2016. Its planning concept of block-type business office is consistent with the trends of promoting residential block system in China. The block-type business office park landscape is required to provide business and communication function, possess the stereoscopic landscape space with vivid and ecological courtyard experience. Landscape planning, bottom boundary and green landscape are key points to achieve the goal of personalized environmental system with the concept of block-type and ecological.
\end{abstract}

\section{Introduction}

Nowadays, it is proposed that the newly built houses should popularize the block system and not build closed ones anymore with an aim to emphasize the publicity of roads. As urban important economic innovation carrier, the opening of theme office parks and the publicity process are under way.

The block-type business office park refers to the park combing offices, commerce and service and closely associated with blocks. In short, it is the combination of office and commerce, which provides both the offices and rich commerce and leisure facilities. The most common form is the upper floors for private and office use and the bottom floors for commerce and public use, forming an open park without walls.

The block-type business office park planning should pay attention to the needs in three aspects: the block system within the urban framework should be extended to the office park, breaking the barrier between parks and the city and achieving the sharing of the park environment, facilities and the city; on the basis of the original urban block network, the park road should be refined and its network should be within 100 to 150 meters to build a suitable walk scale; the relatively closed and inward form of office parks should be broken down and urban roads should be led in.

Although the block-type business office park can improve the land utilization efficiency, make transportation more convenient and possess more commercial energy, it has obvious disadvantages which mainly indicate too large building density, too high plot rate, limited public green area and unitary landscape. The research takes Hefei Financial Village Phase One as the example and investigates how to build block-type business office park landscape with great business atmosphere. Landscaping and greening in the landscape design will be analyzed from the entry point of project planning and positioning.

\section{The Background of Hefei Financial Village Landscape Design}

2.1 Project Introduction. Hefei Financial Village is located in Binhu New District, Hefei, and positioned as a finance theme industrial park. The construction was officially launched in October 2013 by the leading domestic industrial real estate bock operator -- Optics Valley Union who invested 3.5 billion yuan. It occupies 171 mu with about 610 thousand square meter area of construction. 10 office towers, 14 multistory single office buildings, 1 budget hotel, 1 serviced apartment and supporting podiums, conference centers. It can be seen in Figure 1. 


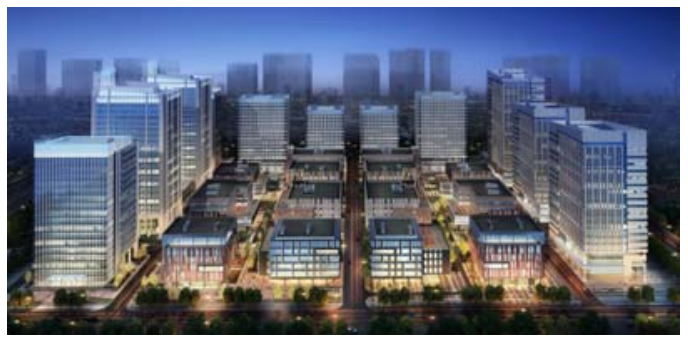

Fig. 1 Project aerial View Fig.

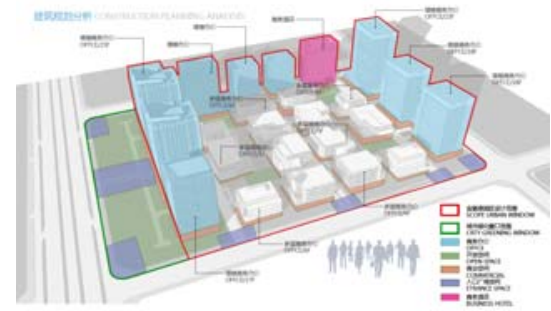

Fig. 2 The Analysis of project design conditions

2.2 The Project Landscape Positioning. The project is positioned as the deep business and petty bourgeoisie block-type business office park in order to advocate a new industrial park pattern and lead a new life style. The landscape is required to provide business and communication function, possess the stereoscopic landscape space with vivid and ecological courtyard experience and become the landscape quality benchmark of the same kind parks.

2.3 The Project Design Conditions. (1) Limited Space

It is used for commercial land and the plot rate is 4.14. The park planning lays out based on the block-type, so the building density is $33.7 \%$ and the greening rate is only $20.4 \%$. The landscape area is relatively small.

(2) Urban Greening Control Tape outside the Red Line

There is 15, 000 square meters of urban greening control tape close to urban main road - Huizhou Avenue project. The green belt will be re-planned by the property developer and incorporated into Hefei Financial Village as the land dealing terms.

(3) Project Single Building Seeks Harmony in Diversity

The project architecture has many single buildings. The design philosophy of inner 14 multistory single buildings is harmony in diversity and the architectural form of each single building is unique. There is the same DNA sense of design among the buildings but each has its own unique disposition and style. Facade materials, colors, accesses, corridors, balconies, terraces and patios are different. It is shown in Figure 2.

2.4 The Project Target Market. Most of the entering enterprises are large financial ones or upstream-downstream industrial chain companies. The major office staff is composed of young white-collars after 80s and 90s. There are common features in work nature, working habits and age structure:

(1) High comprehensive quality and aesthetic insight

The office workers after 80s and 90s who pursue financial industry possess good educational background, broad horizons and higher comprehensive quality. They have certain discernment for environmental design.

(2) Pursuit for office quality and diversified environment

Office workers treat office as a second home, they expect the work environment to be stylish, convenient, quality, fantastic. The development of technology and improvement of decoration create conditions to improve office environment. A modern, technological, warm and free working environment will be popular with office workers.

(3) The common existence of stress and anxiety

Owning to the work nature, time and other aspects, Sick Building Syndrome has a serious impact on the office workers and the physical and mental sub-health has become very common. A relaxed and comfortable working environment not only relieves the stress but also increases working tastes, generates working passion and energy, and improves working efficiency.

\section{The Analysis of Block-type Business Office Park Landscape Design}

With the evolution of key features in various industrial parks and business patterns, the advance in industrial parks can be classified from Phase 1.0 to 4.0 and the park planning, architectural forms and landscape planting have been upgraded. 
The industrial parks in Phase 1.0 give priority to workshop plus road distribution and often ignore the park environment, which presents a feeling of void and bleak factory districts. In Phase 2.0, the environment is elevated to some extent but the planting forms are extensive, the greening amount is not adequate and the outdoor space is the single activity area. In Phase 3.0, the park environment becomes diversified and more stresses humanized design, and the working environment turns more comfortable and pleasant. In Phae 4.0, the concept of block-type and ecological office has appeared and humanized environmental system has been created.

In order to achieve the goal of personalized environmental system with the concept of block-type and ecological in Hefei Financial Village Phase One landscape, three aspects of landscape planning, bottom boundary and landscaping construction are paid more attention in design.

3.1 Landscape Planning. (1) Function Divisions

Landscape function divisions are divided into the peripheral commerce landscape belt, the theme activity zone, the commerce-office fusion zone and the urban greening window in Hefei Financial Village Phase One, combining the architecture function layout. When it comes to the specific park inside, four independent plazas are mapped out, which are positioned as the commerce-office fusion zone, the leisure activity zone, the green office experience zone and the hotel backyard landscape zone exhibited in Figure 3.

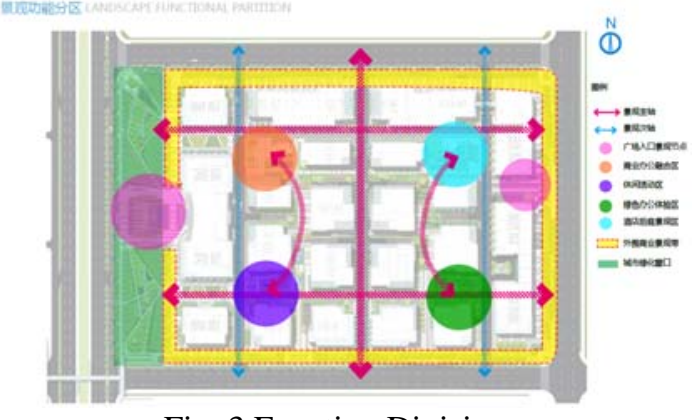

Fig. 3 Function Divisions

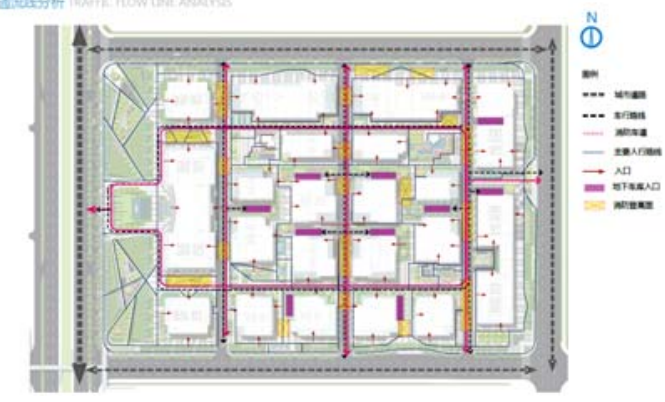

Fig. 4 Traffic Flow Analysis

(2) Traffic Organization

The landscape and road system are staggered, which forms a pedestrian corridor, opened to the city. The landscape agrees with the public opening node and lays emphasis on the combination of points and lines and wise control of measurement.

First of all, the Fast Axis Space is confirmed after examination of road layers and parking space. Then the bottom architecture space is endowed with the Low Axis Space attribute according to the characters of each building. Fast is an interpretation of the project, because finance represents high efficiency and fast speed while Low originates from the satisfaction of space users' relaxed and emotional need, which is expected to become a business and petty bourgeoisie industrial park presenting enterprise culture and humanization. It can be seen from Figure 4 .

3.2 Bottom Boundary Design of Industrial Parks. Bottom boundary refers to its floor space which includes floor pavement, footsteps, outdoor furniture, architecture opuscule, path and other public facilities. The design of floor pavement, footsteps and path in Hefei Financial Village Phase One is very unique.

(1) Floor Pavement

As floor pavement is the most fundamental and important part of landscape bottom boundary, its manifestation pattern and space scope play a significant role in the landscape integrity. The pavement design of Hefei Financial Village has three important roles:

[1] Identification of space use attribute.

Space function and nature determine the pavement pattern, dimensions, color and texture. As the block-type office parks, each architectural monomer first floor is planned as bottom floor commerce except the lobby space at the entrance and exit. The pavement pattern, dimensions and color of the lobby entrance and exit are differentiated from the commerce part. For instance, the pavement pattern is as concise as possible and stone most adopts large dimension board to highlight the dignity, 
generosity and simplicity while the commerce area attaches much importance to personality and vitality. By comparison, the space function attribute is intensified.

The building market of ground floor along Nanjing Road is projected as commercial bank branches. The thickness of pavement stone is $50 \mathrm{~mm}$, after taking into consideration the later frequent in-and-out of people and car flows and inevitable stone looseness and abrasion, normal size with $600 \mathrm{~mm} \times 300 \mathrm{~mm}$ is adopted.

The outer pavement material surface layer mainly uses flamed and litchi surface which demonstrate good performance in water absorption and skid resistance, such as flamed sesame black and litchi dark green of Zhangpu. Brick-kind pavement materials are not used in Hefei Financial Village Phase One except in the municipal green belt because later its surface is likely to adhere to earth and become slippery such as cement brick and sintered brick.

[2] Differentiation of space attribute

Most industrial parks pay little attention to floor pavement when making landscape designs and the material choice and pavement patterns are relatively simple which costs less and facilitates construction, but fails to guarantee the design and quality. According to the business layout arrangement and post-stage operation philosophy, the pavement of Hefei Financial Village has different presentations in the office-commerce zone, the lobby access, the internal and external commerce streets, theme plazas and municipal green belts. For instance, the customized pattern pavement for commerce use and the carriage way mixing sesame white and dark green of zhangpu increase the spatial mobility and seem extremely energetic and dynamic, seen in Figure 5.

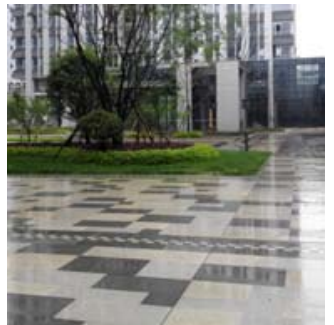

Fig. 5 Pattern Pavement

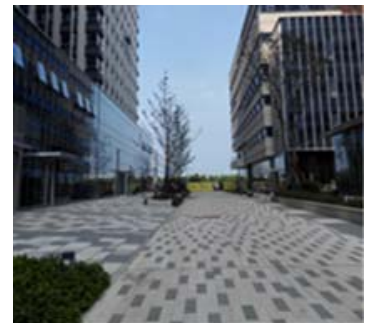

Fig. 6 The Increase of Space Perception

[3] Confinement of space interface

The building density is large and the building interval is limited, but through landscape handling the space scale can be improved effectively. Taking the south carriage way of A5A6 ground floor for example, stones with two contrast colors, sesame white and zhangpu green are adopted for paving materials. They are paved vertically in 4:1 scale and roadside stone height has been lowered, which is only $20 \mathrm{~mm}$ higher than the outer pattern pavement of ground floor. At the same time flow shrubs, benches or flower boxes are placed to limit the range of road on side of curbs. Through the processing above, the longitudinal fluidity of space is improved and the space perception is enhanced. It is presented in Figure 6.

(2) Footsteps and flower bed

Setting footsteps and flower beds is to deal with the field vertical relations and employed flexibly, and have the inherent advantage of managing level differences. The north-south vertical level difference of Hefei Financial Village is close to $2000 \mathrm{~mm}$. \pm 0.000 all use the same level in the architectural design, so many different vertical levels have been formed at the architecture access and along the street.

The vertical level difference between the outer stores alongside Nanjing road and the municipal sidewalks is $1600 \mathrm{~mm}$. The design has considered many factors such as footsteps, slopes, road width and sight lines. In addition, rebate flower beds are used to adjust the paving slope. The refined sweet osmanthus matches hododendron pulchrum, ligustrum japonicum 'Howardii', pittosporum tobira and Loropetalum chinense var.rubrum. The footstep tread is made of $80 \mathrm{~mm}$ thick stone materials which manifests the dignity and generosity of the access. It can be seen in Figure 7 and Figure 8. 


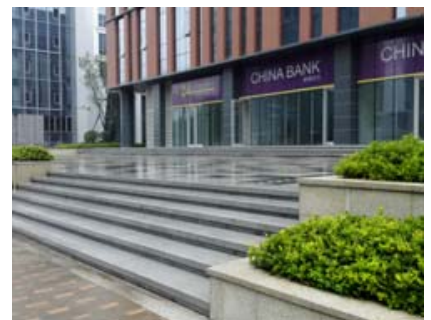

Fig. 7 Footstep treatment

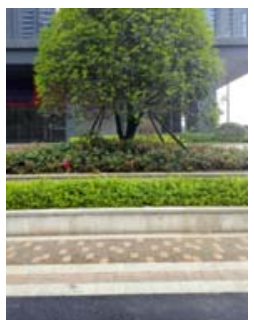

Fig. 8 Rebate Flower bed

(3) Path

Whether the path planning of industrial parks is good or bad is reflected in the rationality of overall spatial order. A good path planning is directive and people can arrive at the destination without visual sign systems and come in and out of parks unblocked and liberally. Regardless of carriage ways or sidewalks, when people walk through the path, the building landscape inside the parks jumps into view and presents people an enjoyable feeling.

The inner streets are composed of many independent office buildings. The elevated ground floor adopts colonnades and combines cantilever balconies and canopies, which guarantees the continuity of each ground floor walk space, make the ground floors more open and fascinating and create more business opportunities and vitality. The path design is intelligent and delicate. It reflects the design methods of block-type business landscape. All paths interact with each other in the combination of flooring, path width, surrounding plants, landscape lamps and dustbins. Commerce outward swaying space has been reserved at business value points and paths extending from small to large forms outdoor terraces. The environment attribute is identified through the changes of path paving materials, which maintains the solemnity of office environments and stress business value points of inner street ground floor. Figure 9 shows the combination of ground floor business and basement light well. People can reach this location according to the path guidance and the post-stage spatial attribute has been reserved through different paving materials.

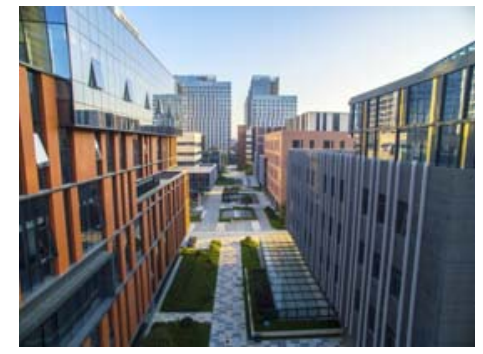

Fig. 9

3.3 Green Landscape. The first impression is of vital importance when visitors enter the park. The architectural image and landscape environment directly represent the image and taste of enterprises.

The greening design of Hefei Financial Village sustains the philosophy of block-type office parks. The whole style centers around modern, concise and comfortable landscape design philosophy. Taking advantage of current terrains and combing function localization and surrounding urban landscape, the green design uses the street trees, grass lands, flowers and landscape trees to set the tone and shapes a financial office park of multiple functions, flexibility, openness and deep business atmosphere according to the partial water and terrain features.

(1) Landscape Central Axis

The natural landscape central axis takes shape regarding the four different function plazas surrounding the road network as the core. The green landscape processing methods are different in each landscape central axis. For example, in the following landscape design picture of the commercial plaza, the emphasis is put on permeability and commercial value. First, based on the high tolerant bamboo flooring platform, colored leaf trees is the main species in the green collocation. Sapium sebiferum, pistacia chinensis and celtis sinensis are picked as the skeleton trees to make decorations. Grasslands and colorful shrubs are combined together according to the rules, paired with 
large scale rigid pavement, in order to tell the function localization differences between this plaza and the other three. These can be observed from Figure 10 and Figure 11.

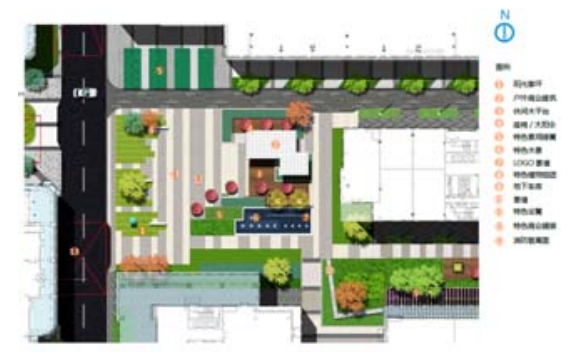

Fig. 10 Commercial Plaza

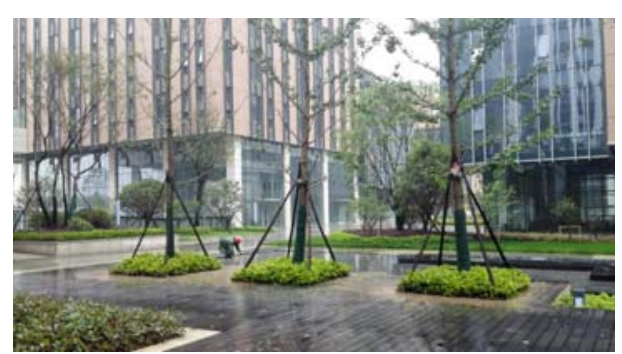

Fig. 11 Sculpture Plaza

(2) Linear Space

The whole landscape arrangement and space image is realized by the spatial definition and transition, the view point change, the guidance and continuity of sights. The various ground floor buildings are well proportioned and the lines are diverse and smooth. The landscape dimension and the architecture supplement each other which elevates the sense of space and quality largely.

In the choice of plants, most of arbors are clustered kind. For instance, clustered pistacia chinensis, celtis sinensis and ligustrun lucidum become the main isolated trees in the space mixed with some native tree species such as camphor, sapium sebiferum, silk trees and koelreuteria paniculata. Ginkgo tree arrays is arranged in the entrance area of the sculpture plaza to emphasize the vertical and district sense. After entering the plaza, people can feel the definite static spatial orientation through the rebate greenbelts, special sculpture and landscape wall to highlight the horizontal sense and identified pavement area, which can be seen in Figure 12. Pistacia chinensis has tall and straight limbs with beautiful shape and the branching node is high. The isolated plants match the waterscape, bringing people the brief, quiet, bright and upbeat visual experience. These can be seen in Figure 13.

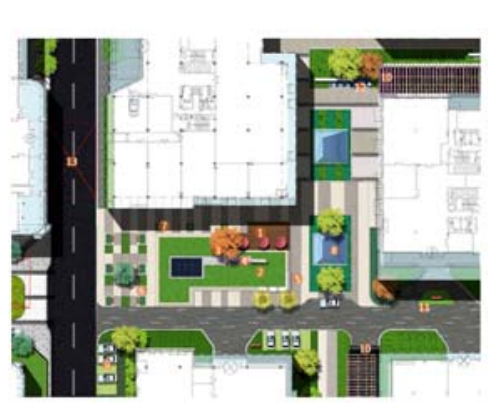

Fig. 12

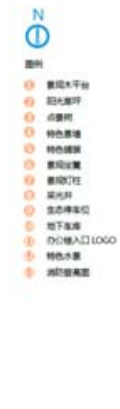

(3) Grassland Space

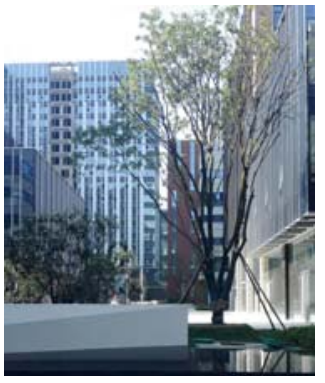

Fig. 13

Grasslands are suitable for landscaping. There are two ways to accomplish the space creation. One is through the physical property of lawns and the other is through artificial process. There exist differences of the color brightness and purity in lawns made of different kinds of grass, which can be used to create different landscapes. Artificially processed grassland shapes are divided into the regular one and the irregular one. Regular lawns are used to create various specific landscapes while the irregular ones are mainly used to control the landscape spatial level.

Taking for example the municipal green belt of Hefei Financial Village Huizhou Avenue, the plants in original municipal greenbelt were planted densely to control urban space green quantity at the beginning and the real intention is to cover the undeveloped city image on two sides. When the architecture image of Hefei Financial Village Phase One is accomplished, the image presentation is very important as the side close to the urban main road. Therefore, when redesigned, it is essential not to block the park image and the brand name of post-stage entering enterprises. To be more specific, first, a large area of wide rebate lawns are located in the area close to the municipal road. This can extend the distance from urban roadside trees, produce a wide visual feeling and let people see the park subject image during driving. Besides, the municipal greenbelts is 50 meter wide, so the rebate lawns can enlarge the spatial sense. And the landscape design of rebate lawns near the park employs 
arbor plus shrub plus ground cover plants, which forms a greening group with different sizes and a visual central point.

It is very hard to have a large area of evergreen lawns, which is a luxurious vision for many office parks because of the geographic location and climate conditions of Hefei. However, Hefei Financial Village has realized it. On one hand, it is important to determine the grassland variety and the earlier stage planting system. In earlier planting stage, the putting green is directly placed and in later stage during season changes, it is necessary to carry out reseeding and mixed sowing. On the other hand, the post-stage maintenance is strengthened to guarantee the maintenance of warm season grass and cold season grass during transition, the promptness and uniformity of reseeding. In the meantime, the projected lawns have set up the sprinkling irrigation system in order to reduce the stress of post -stage maintenance, which can be obtained from Figure 14.

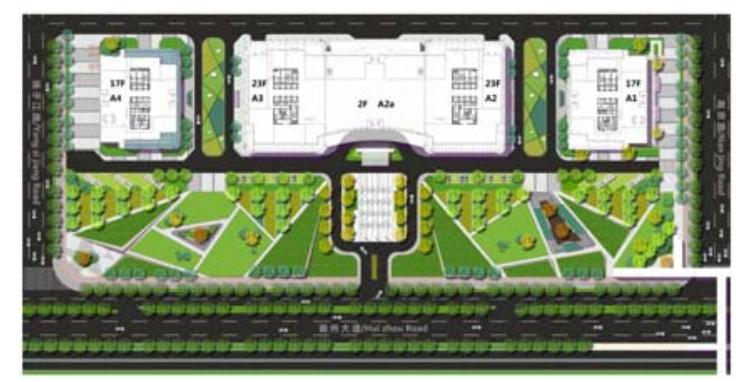

Fig. 14

\section{Conclusion}

Hefei Financial Village Phase One has been put into use. The project overall environment and quality have won consistent praise either from customers' on-site experience during house sales or from owners' feedback after the delivery. It becomes an advantage of project promotion in the sales process compared to similar projects and has a positive effect on the product pricing. A successful landscape project cannot achieve success without the exact understanding and positioning of the project, the format planning, the post-stage predictability and the aesthetic tendency and working needs of target audience. All these factors comply with the trends of industrial park landscape spatial development and act as an important prop for Hefei Financial Village with remarkable landscape design and construction quality in comparison with the similar industrial parks.

\section{References}

[1] Hongxin Li, Zhao Li, Theory of Large Residential District Design and Exploratory Practice, J. ARCHITECTURAL JOURNAL. 4 (2000) 12-15.

Reference to a book:

[2] Chunxiu Chen, Analysis of Hardened Pavement Construction Design in Landscape Engineering, J. URBAN CONSTRUCTION THEORY RESEARCH. 24 (2015)2745-2746.

[3] Fenghua Wen, Tiyan Shen, Industrial Park Systematic Planning: Smart Development for Industrial Parks in Transitional Period, J. Planners. 9(2011) 15-19.

[4] Wei Cheng, Yi Yang, Planning and design of high-tech park, D. Huazhong University of Science and Technology (2004) .

[5] Mingzhi Wei, Lawn in Landscape Design, J. URBAN CONSTRUCTION THEORY RESEARCH. 22(2012) .

Photo Source: Part of photos come from Allied Architects International

Photographer: Yong Zhang

Author Remarks: Thank Peng Fang from Hefei Optics Valley Union for some professional data support in the research. 